\title{
Work ability among hospital food service professionals: multiple associated variables require comprehensive intervention
}

\author{
Frida Marina Fischer ${ }^{\mathrm{a}}$; Maria Carmen Martinez ${ }^{\mathrm{b}}$ \\ ${ }^{a}$ Environmental Health Department., School of Public Health, University of São Paulo. Avenida Dr. Arnaldo, 715 , \\ 01246-904, São Paulo, SP, Brazil \\ ${ }^{\mathrm{b}}$ Epidemiology Nucleus, Hospital Samaritano de São Paulo. Rua Conselheiro Brotero, 1505, cj. 32, 01232-010, \\ São Paulo, SP, Brazil
}

\begin{abstract}
The work of hospital food service is characterized by demands that can be associated with work ability - WA. The aim of this study was to evaluate factors associated with WA among hospital food service professionals and recommend intervention measures. This is a cross sectional study carried out in 2009, conducted in a hospital of São Paulo, Brazil. Participants were $76(96.2 \%)$ of the eligible. They filled out a questionnaire including socio-demographic data, life styles, working conditions and WA. Multivariate linear regression analyses were performed. Factors associated with WA were age $(\mathrm{p}=0.051)$, over commitment $(\mathrm{p}=0.011)$, effort-reward ratio $(\mathrm{p}=0.002)$ and work injuries $(\mathrm{p}<0.001)$. In spite was a young population, age was associated with WA. Association with work injuries is consistent with the theoretical model that demonstrated that health status is the basis to maintain the WA. The association of effort-reward imbalance shows that issues related with work organization are relevant for these workers. The association of overcommittment suggests that workers recognize their responsibility with the therapeutic processes of patients. Results showed a number of features of different nature that should be taken into account when implementing measures to improve the WA, to be applied at different levels: individual, task and institutional.
\end{abstract}

Keywords: work ability evaluation, work stressors, psychosocial factors at work, working conditions, hospital food services

\section{Introduction}

Changes in work organization and work processes brought new challenges to hospital workers. Work activities are performed in environments with increasing complexity. There are significant demands and requirements of efficiency, both financial and technical [22].

Among the numerous services provided by the hospitals, it should be mentioned the food hospital service. The work of these professionals is traditionally characterized by high physical demands and the responsibility to ensure the required nutrition to the therapeutic process . These demands are often associated with negative outcomes, including muscleskeletal disorders and eventually reduced work ability [17].

Few Brazilian studies focused on food service professionals. After an extensive literature search, we did not identify studies exploring associated factors and work ability of the mentioned workers.

The aim of this study was to evaluate factors associated with wok ability among hospital food service professionals and recommend intervention measures. 


\section{Methods}

This is a cross sectional study carried out in 2009 , inserted in a 5 years planned cohort study. It is being conducted in a hospital of the city of São Paulo, Brazil. All 79 individuals working in the studied sector were invited to participate. Those who were on sick leave, maternal leave or on vacation $(n=39)$ were not invited to join the study. Participants were 76 $(96.2 \%)$ of the eligible workers. No significant differences $(p>0.05)$ were observed concerning sex, age, job title and time on the job among those who agreed to participate and those who didn't.

Participants filled out a comprehensive questionnaire including socio-demographic data, life styles, working conditions, and the Brazilian versions of Job Stress Scale[1], Effort-Reward Imbalance ERI[4], Work-Related Activities That May Contribute To Job-Related Pain and/or Injury WRAPI[5] and Work Ability Index - WAI[21]. In this study population, the reliability of the questionnaires was assessed by the Cronbach's coefficient alpha and showed the following results: demand $\alpha=0.66$; control $\alpha=0.61$; social support $\alpha=$ 0.84; effort $\alpha=0.73$; reward $\alpha=0.81$; overcommitment $\alpha=0.78$; WRAPI $\alpha=0.92$; and WAI: $\alpha=0.77$.

A descriptive analysis was performed by using means, standard deviations, minimum and maximum values of the scores attributed to continuous variables and ratios referring to categorical variables. The Kolmogorov-Smirnov test was performed to check adherence of the score of "stress at work" to normal distribution, thus determining the type of statistical tests to be performed. The association between WAI and the continuous variables was initially tested by using Spearman's correlation coefficients (nonparametric variables); as for categorical variables, the Mann-Whitney and the Krüskal-Wallis tests were used. Finally, a multiple stepwise linear regression analysis was conducted and variables showing $\mathrm{p}<0.20$ were included. A $5 \%$ level of significance was used for all performed analyses.

The project was approved by the Ethics Committee of the studied hospital. It followed the principles of the Declaration of Helsinki issued by the World Medical Association. Workers participation was voluntary upon signature of a formal consent.

\section{Results}

\section{Descriptive statistics}

Tables 1 and 2 show the continuous and categorical variables.

Work ability index showed an average of 42.4 points (SD 5.5) on a scale ranging from 7.0 to 49.0 points and $80.39 \%$ of participants showed a WAI score higher than 40 points. Most participants were females $(82.9 \%)$, young $(77.6 \%$ less than 40 years old) - mean age was 35.3(SD 8.4) years, single $(44.0 \%)$ or married or living with a partner $(44.0 \%)$, high school education (58.7\%). Family monthly income ranged from US\$ 735 - 1,224 among 76.7\% of the studied population, and $53.4 \%$ reported some kind or sole responsibility for raising children. Only $34.8 \%$ reported practice of regular physical activities. Overweight or obesity prevailed among $38.2 \%$, and the mean of body mass index was 24.8 (SD 4.1). Seventy-six percent of the workers never smoked and 93.0\% deny regular consumption of alcoholic drinks.

Mean age of participants when they entered the workforce was 15.9 (SD 3.4) yrs. The mean time as a food service professional was 6.4 (SD 6.2) yrs; mean time at this job was 2.9 (SD 3.9) yrs.

They worked an extended number of hours: mean weekly working time (adding those worked at this hospital, in a second job and performing household duties) was 57.0 (SD 13.6).

Workers reported low perception of violence at work (mean of 7.3 points - score 7.0 to 21.0 pints), and WRAPI received a mean of 67.1 (SD 36.5) points out of a 150 points scale.

Demands at work were assigned by $85.5 \%$ of participants as the more prevalent source of stress. This percentage is above the mean cut-off point of this scale. The overall means of the studied population was of 14.9 (SD 2.2) points on a 5.0 to 20.0 points scale. Control at work was favorably reported by participants (overall mean 16.8, SD 2.9), as well as social support at work (overall mean 20.6, SD 3.2). Both scales ranged from 6.0 to 24.0 points. ERI dimensions also received favorable results: efforts (mean 11.8, SD 3.7, at a 6.0 to 30.0 points scale), reward (mean 50.3, SD 5.1, at a 15.0 to 55.0 points scale) and overcommitment (mean 12.9, SD 3.6 , at a 6.0 to 24.0 points scale). Twenty one percent of the study population reported job strain at work (high demand and low control) and 2.9\% an effortreward imbalance. Also, $11.0 \%$ of them reported work injuries and $9.7 \%$ work- related diseases. 
Regarding the shifts, workers were $38.7 \%$ in the morning, $29.3 \%$ in the afternoon, and $10.7 \%$ in night shifts; $21.3 \%$ worked administrative hours.

\subsection{Questionnaires reliability}

The analysis of internal consistency showed the questionnaires registered a Cronbach's alpha higher than 0.73 . The exceptions were control $(\alpha=0.61)$ and demand $(\alpha=0.66)$. There isn't an ideal cut-off point to arbitrate Cronbach's alpha and, more important than judging its merit (good or bad), it is to assess the complexity of the phenomenon one intends to measure [23]. Considering that demand and control are relevant to the study and they are complex factors to be measured, we have decided to maintain them in the analysis.

\subsection{Analysis of associated factors with work ability}

The results of the univariate analysis tests are shown in Tables 1 and 2. Socio-demographic features were not associated with WAI. As for lifestyles, smoking habits and practice of physical exercise was significantly associated with WAI (respectively $\mathrm{p}=0.035$ and $\mathrm{p}=0.040$ ). The occupational characteristics significantly associated with WAI were effort-reward imbalance $(p<0.001)$, social support at work $(\mathrm{p}=0.001)$, overcommitment $(\mathrm{p}=0.004)$. Shift work were significantly associated with WAI $(\mathrm{p}=0.067)$ as well as work-related diseases $(\mathrm{p}<0.001)$.

The multiple linear regression analyses showed the variables that remained independently and significantly associated with WAI (Table 3). The negative associations with the WAI were: effortreward imbalance $(p=0.002)$, former work related diseases- yes $(p<0.001)$, and overcommitment $(\mathrm{p}=0.011)$. The analysis was controlled by age and sex. Shift work was not an independent variable associated with WAI.

\section{Discussion}

Workers showed satisfactory work ability: $80.3 \%$ scored higher than 40 points (out of 49 points). According to the suggested cut-off points of WAI [31], only $13.8 \%$ of the workers reported inadequate (poor or moderate) work ability. The results observed in the current study showed a higher work ability index compared with earlier studies conducted among hospital professionals. In Brazil the observed prevalence were around $22.8 \%$ and $38.9 \%[9,25]$, and in Europe they were between 11.0 to $42.0 \%$ among hospital workers $[2,6,8,12]$ The study participants of the mentioned studies have quite distinct sociodemographic (such as sex, age and lifestyles) and occupational features (such working conditions, roles, responsibilities), compared to those previously studied. Due to these features is being rather difficult to compare results looking at the work ability index in different regions and other job titles. As mentioned in the introduction section, former work ability studies among food service hospital workers were not found.

Previous studies looking at work- related health outcomes among hospital professionals showed multiple variables, such as sociodemographic characteristics, lifestyles, working conditions and health outcomes, associated with work ability $[9,12,19,25,26]$. In this study it was observed similar factors but they lost significance when performed the multivariate analyses. Factors that remained significant were: work stressors (effort-reward imbalance and overcommitment) and work related disease. This is in accordance with the "house of work ability", a concept which comprised a hierarchical model. The work and all of their dimensions (environment, content, demands, work community, and organization, including supervision and management) is the largest and heaviest floor of this house, and it sets the standards for the other floors [15]. In this study population despite the perception of high work demands and work environment that may favor the occurrence of pain and injuries, the organizational and social context defined by ERI score - including financial rewards, esteem at work and career opportunities - are at least as important as work demands and a healthy work environment. ERI has been shown to be an important work ability indicator, more relevant than other variables that are traditionally explored in other studies about the same subject [11,28]. A similar conclusion was published by the NEXT study [12] stressing the importance of the imbalance between effort and reward. As mentioned by Hasselhorn et al. (2004), an intervention in this aspect will help to reduce the "burden of distress" [13].

The overcommitment was also associated with work ability. In the present study it is other source of stress, and has been observed in other studies of hospital workers [6, 29]. Overcommitment is a motivational pattern of excessive work-related performance and achievement, reinforced by external work pressure. In the long run, it can lead to exhaustion and adaptive breakdown and work stress 
[27]. In this study population, the association between overcommittment and work ability suggests that workers recognize their responsibility and are committed to the therapeutic process of the patients. The widespread prevalence of high job demands in this population as well as the relevance of psychosocial factors expressed by the effort-reward imbalance, and overcommittement may explain why a particular shift was not associated with work ability. It suggests homogeneity of the afore mentioned occupational characteristics across different shifts. Moreover, although this population has entered quite young in the job market, but they were working at this job for a short time, and thus, the long-term effects of night or shiftwork may not have manifested [7].

As expected, WAI was associated with the occurrence of work-related diseases, one of the variables retained on the final regression model. This result also is in accordance with "house of work ability" model, which presents in its' ground floor the potential use of human resources - health status, including physical, mental and social functioning [48] that will eventually be reduced by work diseases.

As reported in the literature, food service professionals routinely deal with risk-prone working conditions associated with musculoskeletal disorders. [17]. As a consequence the main medical diagnoses are musculoskeletal diseases $[14,17]$. In this present study, health-related outcomes measured by work ability were lesions due to work injuries (28.9\%), respiratory infections (17.1\%), and musculoskeletal disorders (15.8\%). Analyses were controlled by sex. And although it did not appear associated with work ability in this population is recognized for its association with functional aging. Several studies highlight that females have higher risk of impairment of their work ability than men. It is likely to be influenced by worse working conditions, including wages [24,32]. It is also worth to be mentioned that females usually carry a higher burden compared to men, of being responsible for household duties and the responsibility of raising small children, and thus inducing a significant family-conflict $[3,9,25,26]$. As females are the majority of employees in hospital food service sector, including in the present study, it should not be ruled out the importance of managers' special attention to their professional as well as domestic duties that might interfere in their health status and wellbeing $[3,9,13]$. Age was not associated with work ability and also entered as a control variable in the analysis. The association pattern that relates chronological and functional aging was described in several studies. However, it is not always linear and may be absent, showing the influence of other factors mediating this relationship $[16,20]$.

The cross-sectional design of this study does not allow establishing causal associations. This design also prevented the inclusion of workers that were absent from work for medical reasons, including those who suffered severe work related diseases and were on sick/injury leave. However, as the response rate for the present study was $96.2 \%$, thus above the $75.0 \%$ considered adequate [10], the internal validity of this study can be accepted. And the external validity can be extended for food service professionals of hospitals having similar characteristics on demographic, working conditions and work organization.

Despite the high participation rate in this study, a healthy worker effect is likely to be present in this study population, and could lead to a selected population working during the day or at night [18]. If this is true, then the associations between working conditions and WAI presented here underestimate the true effect.

The present study enabled us to characterize work ability among hospital food service workers and its associated factors. This should be taken into account when planning and implementing measures to maintain work ability among professionals of this hospital. Intervention activities derived from the results of this study must consider different levels: the individual level, the interpersonal level of social exchange at the worksite, and the structural level of work organization. At the individual level, it was proposed: customize health monitoring; healthier meals provided by the employer; and incentives to do physical activities during leisure time. At the tasks level, it was proposed: ergonomics evaluation aiming tasks and workplaces redesign, replacing of equipment, particularly food trolleys by lighter and smaller ones, review of professional profile and coaching managers to deal with difficulties and work improvements. At the institution level was recommended: continuing educational programs, opportunities for professional career development, financial rewarding and incentives for work recognition.

The results presented here are part of a cohort study that was initiated in 2008. A follow up of 5 years is planned. Considering the limitations of the cross-sectional study design and the scarcity of studies on work ability among Brazilian hospital food 
services, this cohort study would allow identifying causal relationships, cost-benefits and cost-utility studies to evaluate the implemented interventions, as well as other outcomes related to the work ability, health status and wellbeing.

\section{Conclusions}

Factors associated with work ability are of different nature. These results showed a number of features should be taken into account when planning and implementing measures to maintain or improve the work ability among hospital food service professionals.

Individual features, working conditions and healthrelated work outcome- work injuries- were associated with work ability among hospital food service professionals. These results showed that a number of features should be taken into account when planning and implementing measures to maintain work ability among hospital nursing staff. The use of WAI as a management tool would help to improve the identification of populations at risk and to enable development of specific intervention activities of health promotion.

\section{Acknowledgments}

FM Fischer is a grant recipient from CNPq- a Brazilian Research Agency;

We would like to thank the hospital management for their support and the study participants.

\section{References}

[1] M.G.M. Alves, D. Chor, E. Faerstein, C.S. Lopes and G.L. Wenerck, Short version of the "job stress scale": a Portuguese-language adaptation, Revista de Saúde Pública 38.2 (2004), 164-171.

[2] D. Camerino, P.M. Conwaya, B.I.J.M. van der Heijden, M. Estryn-Béhar, G. Costa and H.-M. Hasselhorn, Age-dependent relationships between work ability, thinking of quitting the job, and actual leaving among Italian nurses: A longitudinal study, International Journal of Nursing Studies 45.11 (2008), 1645-1659.

[3] D. Camerino, M. Sandri, S. Sartori, P.M. Conway, P. Campanini and G. Costa, Shiftwork, work-family conflict among Italian nurses, and prevention efficacy, Chronobiology International 27.5 (2010), 1105-1123.

[4] D. Chor, G.L. Wenerck, E. Faerstein, M.G.M. Alves and L. Rotenberg, The Brazilian version of the effort-reward imbalance questionnaire to assess job stress, Cadernos de Saúde Pública 24.1 (2008), 219-224.

[5] M.Z.O. Coluci and N.M.C. Alexandre, Adaptação cultural de instrumento que avalia atividades do trabalho e sua relação com sintomas osteomusculares, Acta Paulista de Enfermagem 22.2 (2009), 149-154.

[6] P.M. Conway, P. Campanini, S. Sartoria, R. Dotti and G. Costa, Main and interactive effects of shiftwork, age and work stress on health in an Italian sample of healthcare workers, Applied Ergonomics 39.5 (2008) 630-639.

[7] G. Costa, L. Di Milia, Aging and shift work: a complex problem to face, Chronobiology International 25.2 (2008), 165-181.

[8] M. Estryn-Behar, G. Kreutz, O. Le Nezet, L. Mouchot, D. Camerino, R.K. Salles, E. Ben-Brik, J.P. Meyer, J.F. Caillard, H.-M. Hasselhorn and the NEXT study group. Promotion of work ability among French health care workers - value of the work ability index, International Congress Series 1280 (2005), 73-78.

[9] F.M. Fischer, F.N.S. Borges, L. Rotenberg, M.R.D.O. Latorre, N.S. Soares, P.L.F.S. Rosa, L.R. Teixeira, R. Nagai R, J. Steluti and P. Landsbergis, Work ability of health care shift workers: what matters?, Chronobiology International 23.6 (2006), 1165-1179.

[10]D.J. Fowler Jr, Nonresponse: implementing a sample design, in: Survey research methods, Sage Publications, California, 1990, pp.45-60.

[11]R.H. Griep, L. Rotenberg, P.Landsbergis and P.R. Vasconcellos-Silva, Combined use of job stress models and self-rated health in nursing, Revista de Saúde Pública 45.1 (2011), 145-152.

[12]H.-M. Hasselhorn, B.H. Müller, P. Tackenberg and NEXTStudy Group. NEXT Scientific Report - July 2005 (2005). Report of the Next-Study, University of Wuppertal, Wuppertal.

[13]H.-M. Hasselhorn, P. Tackenberg, R. Peter and NEXT-Study Group, Effort-reward imbalance among nurses in stable countries and in countries in transition, International Journal of Occupational and Environmental Health 10.4 (2004), 401408.

[14]E. Haukka, P. Leino-Arjas, S. Solovieva, R. Ranta, E. ViikariJuntura and H. Riihimäki, Co-occurrence of musculoskeletal pain among female kitchen workers, International Archives of Occupational and Environmental Health 80.2 (2006), 141148.

[15]J. Ilmarinen, R. Gould, A. Järvikoski and J. Järvisalo, Diversity of work ability, in: Dimensions of Work Ability, R. Gould, J. Ilmarinen, J. Järvisalo and S. Koskinen, eds., Waasa Graphics Oy, Vaasa, Finland, 2008, pp.13-24.

[16]J. Ilmarinen, K. Tuomi and M. Klockars, Changes in the work ability of active employees over an 11-year period, Scandandinavian Journal of Work, Environment \& Health 17.Suppl 1 (1997), 49-57.

[17] A.A. Jorge, D.M.R. Glina, M. Isosaki, A.C. Ribeiro, M. Ferreira Junior and L.E. Rocha, Distúrbios osteomusculares do trabalho: fatores de risco em trabalhadores de nutrição hospitalar, Revista Brasileira de Medicina do Trabalho 7 (2009), 2-10.

[18]J. Last, A Dictionary of Epidemiology, Oxford University Press, New York, 1998, pp.114.

[19] P.M. Lindfors, O.A. Meretoja, S.M. Töyry, R.A. Luukkonen, M.J. Elovainio, and T.J. Leino, Job satisfaction, work ability and life satisfaction among Finnish anaesthesiologists, Acta anaesthesiologica scandinavica 2007; 51.7: 815-822.

[20] M.C. Martinez and M.R.D.O. Latorre, Health and work ability among office workers, Revista de Saúde Pública 40.5 (2006), 851-858.

[21] M.C. Martinez, M.R.D.O. Latorre and F.M. Fischer, Validity and reliability of the Brazilian version of the Work Ability Index questionnaire, Revista de Saúde Pública 43 (2009), 525532.

[22] J. Needleman, P.I. Buerhaus, M.Stewart, K. Zelevinsky and S. Mattke, Nurse Staffing in Hospitals: Is There a Business Case for Quality?, Health Affairs 25.1 (2006), 204-211. 
[23]J.C.R. Pereira, Processamento e análise de variáveis qualitativas, in: Análise de dados qualitativos: estratégias metodológicas para as ciências da saúde humanas e sociais, EDUSP, São Paulo, 1990, pp. 77-100.

[24]M.M. Perkiö-Mäkelä, Finnish Farmer's self-reported morbidity, work ability and functional capacity, Annals of Agricultural and Environmental Medicine 7.1 (2000), 11-16.

[25]L. Rotenberg, R.H. Griep, F.M. Fischer, M.J.M. Fonseca and P. Landsbergis, Working at night and work ability among nursing personnel: when precarious employment makes the difference, International Archives of Occupational and Environmental Health, 82.7 (2009), 877-885.

[26]L. Rotenberg, L.F. Portela, B. Banks, B.H. Griep, F.M. Fischer and $\mathrm{P}$. Landsbergis, $\mathrm{A}$ gender approach to work ability and its relationship to professional and domestic work hours among nursing personnel. Applied ergonomics 39.5 (2008), 646-652.

[27]J. Siegriest, Effort-reward imbalance and health in a globalized economy, Scandinavian Journal of Work, Environment \& Health 34.6.Suppl (2008), 163-168.
[28] A.A. Silva, J.M.P. Souza, F.N.S. Borges and F.M. Fischer, Health-related quality of life and working conditions among nursing providers, Revista de Saúde Pública 44.4, (2010) 71825.

[29] S.H.A. Silva Junior, A.G.G. Vasconcelos, R.H Griep and L. Rotenberg, Validade e confiabilidade do índice de capacidade para o trabalho (ICT) em trabalhadores de enfermagem, Cadernos de Saúde Pública 27.6 (2011), 1077-1087.

[30]K. Tuomi, P. Huuhtanen, E. Nykyri and J. Ilmarinen, Promotion of work ability, the quality of work and retirement, Occupational Medicine 51.5 (2001), 318-324.

[31] K. Tuomi, J. Ilmarinen, A. Jahkola, L. Katajarinne and A. Tulkki, Índice de capacidade para o trabalho, EduFSCar, São Carlos, 2005.

[32]I.A.P. Walsh, S. Corral, R.N. Franco, E.E.F. Canetti, M.E.R. Alem and H.J.C.G Coury HJCG, Capacidade para o trabalho em indivíduos com lesões músculo-esqueléticas crônicas, Revista de Saúde Pública 38.2 (2004), 149-156.

Table 1

Descriptive statistics and univariate association with work ability index for continuous variables, Food Service Personnel, São Paulo, Brazil, 2009.

\begin{tabular}{|c|c|c|c|c|c|c|c|c|}
\hline Variables & $\mathrm{n}^{\mathrm{o}}$ & Mean & Median & $\begin{array}{l}\text { Standard } \\
\text { deviation }\end{array}$ & $\begin{array}{l}\text { Mini- } \\
\text { mum }\end{array}$ & $\begin{array}{l}\text { Maxi- } \\
\text { mum }\end{array}$ & $\mathrm{r} *$ & $\mathrm{p}$ \\
\hline Age & 76 & 34.0 & 33.4 & 8.4 & 19.7 & 59.6 & 0.159 & 0.170 \\
\hline Body mass index $\left(\mathrm{Kg} / \mathrm{m}^{2}\right)$ & 74 & 24.8 & 24.2 & 4.1 & 18.9 & 35.9 & -0.038 & 0.745 \\
\hline Entered age at the workforce (years) & 76 & 15.9 & 16.0 & 3.4 & 8.0 & 24.0 & -0.046 & 0.695 \\
\hline $\begin{array}{l}\text { Time as a food service professional } \\
\text { (years) }\end{array}$ & 75 & 6,4 & 4,0 & 6,2 & 1,0 & 25,0 & 0.02 & 0.865 \\
\hline Time on the job (years) & 76 & 2,9 & 1,7 & 3,8 & 0,2 & 19,7 & -0.02 & 0.864 \\
\hline Total working hours (week) & 60 & 57,0 & 53,5 & 13,6 & 37,0 & 97,0 & 0.022 & 0.870 \\
\hline Violence at work ( 7.0 to 21.0 points) & 72 & 7,3 & 7,0 & 0,7 & 7,0 & 11,0 & -0.169 & 0.156 \\
\hline $\begin{array}{l}\text { Work activities that may contribute } \\
\text { to pain / injury ( } 0.0 \text { to } 150.0 \text { points })\end{array}$ & 69 & 67,1 & 69,0 & 36,5 & 0,0 & 135,0 & -0.138 & 0.257 \\
\hline Demand (5.0 to 20.0 points) & 75 & 14,9 & 15,0 & 2,2 & 9,0 & 19,0 & 0.032 & 0.788 \\
\hline Control ( 6.0 to 24.0 points) & 72 & 16,8 & 17,0 & 2,9 & 9,0 & 23,0 & 0.033 & 0.784 \\
\hline Social support ( 6.0 to 24.0 points) & 74 & 20,6 & 21,5 & 3,2 & 13,0 & 24,0 & 0.384 & 0.001 \\
\hline $\begin{array}{l}\text { Effort-reward imbalance score }(0.17 \\
\text { to } 5.00 \text { points })\end{array}$ & 68 & 0.5 & 0.4 & 0.2 & 0.2 & 1.3 & -0.502 & $<0.001$ \\
\hline Overcommitment ( 6.0 to 24.0 points) & 75 & 12.9 & 13.0 & 3.6 & 6.0 & 24.0 & -0.332 & 0.004 \\
\hline
\end{tabular}

* Spearman's correlation coefficients 
Table 2

Descriptive statistics and univariate association with work ability index for categorical variables. Food Service Personnel, São Paulo, Brazil,

\begin{tabular}{|c|c|c|c|c|c|}
\hline Variables & $\mathrm{n}^{\mathrm{o}}$ & $\%$ & Median & $\begin{array}{l}\text { Standard } \\
\text { deviation }\end{array}$ & $\mathrm{p}$ \\
\hline \multicolumn{6}{|l|}{$\operatorname{Sex}$} \\
\hline Female & 63 & 82.9 & 42.2 & 5.5 & $0.179^{*}$ \\
\hline Male & 13 & 17.1 & 43.7 & 5.7 & \\
\hline \multicolumn{6}{|l|}{ Married Status } \\
\hline Single & 33 & 44.0 & 42.6 & 4.6 & $0.731^{\S}$ \\
\hline Married / Living with a partner & 33 & 44.0 & 42.2 & 6.9 & \\
\hline Single / Divorced / Widowed & 9 & 12.0 & 42.6 & 3.0 & \\
\hline \multicolumn{6}{|c|}{ Family monthly income (U.S.dollars) } \\
\hline$<735$ & 35 & 47.9 & 43.1 & 5.2 & $0.494^{\S}$ \\
\hline $736-1.224$ & 21 & 28.8 & 40.5 & 7.2 & \\
\hline $1,225-2,447$ & 11 & 15.1 & 43.3 & 2.7 & \\
\hline$>2,447$ & 6 & 8.2 & 43.8 & 5.3 & \\
\hline \multicolumn{6}{|l|}{ Schooling } \\
\hline Fundamental school & 11 & 14.7 & 42.0 & 6.8 & $0.557^{\S}$ \\
\hline High school & 44 & 58.7 & 41.7 & 5.9 & \\
\hline College & 20 & 26.7 & 43.8 & 3.7 & \\
\hline \multicolumn{6}{|l|}{ Responsibility for raising children } \\
\hline No & 35 & 46.7 & 43.0 & 4.4 & $0.720^{\S}$ \\
\hline Sporadically & 2 & 2.7 & 39.0 & 8.5 & \\
\hline Yes & 38 & 50.7 & 42.0 & 6.4 & \\
\hline \multicolumn{6}{|l|}{ Smoking habits } \\
\hline Never smoked & 57 & 76.0 & 41.6 & 5.9 & $0.035 *$ \\
\hline $\begin{array}{c}\text { Smoker / Smoked. but stopped } \\
\text { Alcohol intake }\end{array}$ & 18 & 24.0 & 44.9 & 3.1 & \\
\hline 0 to 1 day / week & 66 & 93.0 & 42,6 & 5,1 & $0,280^{(\mathrm{M})}$ \\
\hline 2 or more days / week & 5 & 7.0 & 43,2 & 4,3 & \\
\hline \multicolumn{6}{|c|}{ Regular practice of physical exercise } \\
\hline Yes & 24 & 34.8 & 44.3 & 4.9 & $0.040 *$ \\
\hline No & 45 & 65.2 & 42.3 & 4.7 & \\
\hline \multicolumn{6}{|l|}{ Shift work } \\
\hline Administrative & 16 & 21.3 & 42.9 & 4.0 & $0.067^{\S}$ \\
\hline Morning & 29 & 38.7 & 41.8 & 5.6 & \\
\hline Afternoon & 22 & 29.3 & 41.4 & 6.8 & \\
\hline Night & 8 & 10.7 & 46.5 & 2.4 & \\
\hline \multicolumn{6}{|l|}{ Work related diseases } \\
\hline No & 65 & 89.0 & 43.4 & 4.4 & $<0.001 *$ \\
\hline Yes & 8 & 11.0 & 36.5 & 5.6 & \\
\hline
\end{tabular}

* Mann-Whitney test ${ }^{\S}$ Kruskal-Wallis test

Table 3

Multiple linear regression model for variables associated with work ability, - Food Service Staff, São Paulo, Brazil, 2009.

\begin{tabular}{lcccc}
\multicolumn{1}{c}{ Variables } & $\beta$ & Inf. & $\mathrm{IC}_{95 \%}(\beta)$ & $\mathrm{p}$ \\
\hline Effort-reward imbalance score $(0.17$ & -9.034 & -14.483 & -3.586 & 0.002 \\
to 5.00 points) & -6.396 & -9.563 & -3.230 & 0.465 \\
Work- related diseases & -0.375 & -0.660 & -0.089 & $<0.001$ \\
Overcommitment & 0.118 & 0.000 & 0.236 & 0.011 \\
Age & 0.817 & -1.666 & 3.300 & 0.051 \\
Sex & & & 0.513 \\
\hline
\end{tabular}

